www.periodicos.unimontes.br/index.php/caminhosdahistoria

\title{
TURBULÊNCIA DE IDEIAS: SÍLVIO ROMERO, ENTRE A CRÍTICA LITERÁRIA E A SOCIOLOGIA DE SEU TEMPO (1851-1914)
}

\author{
Cícero João da Costa Filho ${ }^{1}$
}

Recebido em: 21/02/2020

Aprovado em: 25/04/2020

Resumo: Sílvio Romero foi um importante interprete do Brasil, da década 1870. Imbuído de ideias naturalistas, oriundas da Europa, o polígrafo combateu a visão tupiniquim do romantismo brasileiro, alegando ser esta uma visão irreal, mística e fantasiosa. Polêmico e preocupado com questões pertinentes ao progresso do país, Romero se enveredou pelos ensinamentos de Le Play, com o objetivo de esquadrinhar as diversas regiões do Brasil, se certificando da índole do brasileiro, para repará-lo. Escrevendo em tom de denúncia, Romero polemizou com diversos escritores, acreditando na força da ciência e de seus estudos, influenciados por Spencer, Gobineau, Ammon e Lapouge. Nacionalista e inquieto, Romero buscou encontrar o brasileiro a partir do que acreditava ser sua fundamentação, no caso, seu caráter, se desdobrando em valores e atributos morais. Constando a índole apática do brasileiro, apostou nas observações da Escola de Le Play para reparar o quadro pobre e miserável do Brasil de sua época.

Palavras-chave: Silvio Romero; Escola de Le Play; Raça; Positivismo; Brasil.

Abstract: Sílvio Romero was an importante interpreter of Brazil, from the 1870s. Imbued with naturalistic ideas, originating from Europe, the polygraph fougt the tupiniquim view of brazilian romantiscism, claiminng that this was na unreal, mystical and fanciful view. Controversial and concerned with issues pertinente to the country's progress, Romero embarked on the teachings of Le Play, with the aim of scanning the various regions of Brazil, making sure that the nature of the Brazilian, to repair it. Writing in a tone of denunciation, Romero disputed with several writers, believing in the strength of Science and its studies, influenced by Spencer, Gobineau, Ammon and Lapouge. Nationalist and restles, Romero sought to find the Brazilian from what he believed to be his foundation, in this case, his character, unfolding in values and moral atributes. Being the apathetic nature of the Brazilian, he bet on the observations of the School of Le Play to repair the poor and miserable picture of Brazil of his time.

Keywords: Sílvio Romero, Le Play School, Race, Positivism, Brazil.

Resumen: Sílvio Romero fue un intérprete importante de Brasil, desde la década de 1870. Imbuido de ideas naturalistas, procedentes de Europa, el polígrafo fougt la vista tupiniquim del romanticismo brasileño, reclamando que esta era na irreal, mística y fanciful vista. Controvertido y preocupado por temas relacionados con el progreso del país, Romero se

\footnotetext{
${ }^{1}$ Doutorado e pós-doutorado pela Faculdade de Filosofia, Letras e Ciências Humanas da Universidade de São Paulo. Cursa o pós-doutorado com a pesquisa Do feixe à pena, um "fascista democrata": uma análise do Estado brasileiro na Obra Política de Miguel Reale (1931-1937), sob a supervisão da Prof." Maria Aparecida de Aquino. E-mail: cicerojoaofilho@ gmail.com. ORCID: https://orcid.org/0000-0001-5246-8201.
} 
embarcó en las enseñanzas de Le Play, con el objetivo de explorar las diversas regiones de Brasil, asegurándose de que la naturaleza del brasileño, para repararlo. Escribiendo en um tono de denuncia, Romero discutió com vários escritores, creyendo em la fuerza de la ciência y sus estúdios, influenciados por Spencer, Gobineau, Ammon y Lapouge. Nacionalista y inquieto, Romero buscó encontrar al brasileño de lo que él creia que era su fundamento, em este caso, su carácter, desenvolviendose em valores y atributos morales. Siendo la natureza apática del brasileño, por lais observaciones de la Escuela de Le Play para reparar la pobre y miserable imagen de Brasil de su tempo.

Palabras clave: Sílvio Romero, Le Play School, Raza, Positivismo, Brasil.

\section{Introdução}

Crítico literário por profissão, ensaísta, bacharel e professor da renomada Faculdade de Direito do Recife, autor de uma sistematizada História da literatura Brasileira (1960), Sílvio Romero ganhou notoriedade no cenário intelectual brasileiro por seu caráter polêmico, destruindo tudo e todos, matando seus adversários com sua hábil capacidade de agressão. Mas, a este ensaísta preocupado com os mais diversos problemas do Brasil de sua época, nascido em Lagarto, em 1851, as interpretações brasileiras ganham foros de verdade, de ciência, a partir de seu naturalismo literário, divulgada em sua obra mestre, que é História da Literatura Brasileira

Extremo conhecedor de inúmeros livros de ciência e de filosofia que lhe caíam às mãos, sintonizado com as mais variadas correntes de pensamento europeias, Sílvio Romero aderiu primeiramente ao Positivismo de Comte, preterindo o autor do Cours de Philosophie Positive pelas ideias de Spencer, que pregava a questão de struggle for life que conhecera quando estudante de Direito no Recife. Do Positivismo, reconheceu a validade das leis dos três estágios, embora tenha desferido duras críticas ao sistema de Comte por impedir a liberdade ou o desenvolvimento da ciência, devido a seu 'círculo de ferro'. Creditara à raça branca a maior contribuição na formação do povo brasileiro por considera-la a raça mais forte, estendendo a ideia de seleção natural para o campo social, moral e das ideias. Para Sílvio, foi o branco a raça que mais contribuiu para a formação da singularidade brasileira refletida pela figura do mestiço, que era o genuinamente brasileiro ou o brasileiro por excelência.

\section{Influencias sociológicas}

Um dos mestres segundo o próprio Romero era Spencer, fazendo com que o crítico literário argumentasse a lei da evolução no processo social: “Os que sabemos ser a lei máxima 
de todos os fenômenos da história, como a de todos os fenômenos do mundo físico, a lei da evolução, cuja fórmula mais completa é aquela que é devida ao gênio de Herbert Spencer" (ROMERO, 2001, p.65). Mesmo de forma ambígua defendia a originalidade da cultura brasileira, em detrimento da herança racial portuguesa, daí seu brasileirismo onde mesmo reconhecendo a forte herança lusitana, buscou por meio de seus recortes naturalistas identificar aquele escritor que mais refletia a alma nacional brasileira.

Para analisar o Brasil, Sílvio guiou-se pela Escola Social de Le Play e seus divulgadores (Desmoulins, Rousiers, Preville, Bureau), afirmando que "os processos da Escola de Le Play fizeram-me penetrar mais fundo na trama interna das formações sociais e completar as observações exteriores de ensino spcenriano. Uma confirmação, em última instância, de conclusões obtidas por outros meios e estradas" (ROMERO, 1960, p.189). Outra forte influência sofrida por Sílvio foi à Antroposociologia, terceira e última fase de seu pensamento, aderindo ao pensamento radical racista, pontuada por nomes como os de Gobineau, Lapouge, Quatrefagez, Ammom, Topinard, que o fizeram estudar o Brasil à luz do caráter étnico, levando-o a esmiuçar todas as regiões do Brasil para além do critério das raças.

Estas três influências são cruciais para a leitura que Sílvio faz do Brasil. Traçando um quadro social brasileiro nada promissor, ora em função do caráter étnico da 'psicologia nacional' apática e desinteressada pelos problemas nacionais do país, ora devido a um meio propício ao surgimento de verdadeiros clãs políticos responsáveis pela miséria de milhões de pessoas, tudo isto somado ao desconhecimento das elites brasileiras em relação às novas ideias da Crítica Moderna.

\section{Olhando o Brasil: teorias alienígenas, mas eram as de seu tempo!}

Como era regra em sua época, Sílvio interpretou o Brasil munido com os parâmetros exteriores, o que não significa dizer que suas análises tenham se mantido semelhantes à da geração anterior, no caso, a do romantismo. É avançando, diferenciando-se, trazendo o novo, o 'moderno' custe o que custar, que a figura de Sílvio abre uma nova maneira de enxergar a realidade brasileira. Para Sílvio, tanto a elite econômica como a ilustrada, formada por médicos, literatos e jornalistas, não enxergavam as raízes dos verdadeiros males nacionais, esboçando sempre um 'Brasil irreal', de Haia, criticava ainda a mania de passar por aquilo que não somos! Para além das análises raciais, conforme Antonio Candido, Sílvio realizou uma crítica sociológica, escrevendo verdadeiros ensaios políticos, e não uma crítica literária, mas é justamente daí que reside o sentido de recuperarmos as análises daquele. Preso as 
correntes do naturalismo europeu, ao passo que encontramos figuras como as de Araripe Júnior e Capistrano de Abreu credenciando o meio geográfico como determinante na formação da cultura brasileira, Silvio se ligou à categoria racial e climática para explicar o atraso brasileiro, mas o bacharel sergipano ampliava suas análises a um quadro bastante complexo - veja, por exemplo, a concepção que este tinha por meio social - esmiuçando as zonas sociais brasileiras, buscando compreender o caráter do brasileiro, influenciado que foi pela Escola de Le Play.

Desse modo, mesmo se apoiando em autores deterministas como Buckle, discordou de algumas de suas ideias, mas não de sua teoria, em razão de o autor inglês ter dedicado somente oito páginas sobre o Brasil sem nunca ter visitado o país. Mesmo adotando a teoria do meio ambiente exposta em History of civilization England, afirmou que a visão do escritor era "cosmológica demais", carecendo, pois, de um "nexo causal" (ROMERO, 1960, p. 63) A influência de Buckle, de Taine e da corrente de Antroposociologia levou Sílvio a estudar as diversas zonas sociais do Brasil para traçar um quadro geral, onde ele acreditava descobrir o caráter ou a índole do brasileiro. Frente a tantas leituras, reconhecia que o meio brasileiro (clima, temperatura, geologia, geografia) era o "agente diferenciador", sendo o mestiço a singularidade brasileira. Afirmou que "a ação do clima tem contribuído para nossa integração nacional; na literatura, ela tem ajudado a efusão sentimental de nosso lirismo mais doce, suave e ardente do que o lirismo herdado dos portugueses" (ROMERO, 1960, p.96). O meio ambiente era de inteira importância, segundo Romero, para explicar porque "não temos filosofia, nem ciência, nem a grande poesia impessoal dos grandes gênios europeus. Temos o palavreado da carolice, a mística ridícula do beatério enfermo e fanático, de um lado, e de outro, os devaneios fúteis da impiedade impertinente e fácil; na poesia, o lirismo subjetivista, mórbido, inconsistente, vaporoso, nulo" (ROMERO, 1960, p.93-94)

Analisando o Brasil miserável ao longo dos quatro séculos de escravidão, Romero concluiu que "a ação do meio físico em sociologia e na literatura pode-se determinar pelo clima, pelo aspecto geológico e topográfico do país, pela alimentação do povo" (mais que o meio ambiente, portanto). (ROMERO, 1960, p. 95). Poligenista e crente na diferença inata das raças como fator de fundamental relevância, Romero estendeu o critério etnográfico, que dizia ter introduzido entre nós, às explicações sociais buscando compreender o verdadeiro Brasil, o que tanto motivou e deu sentido a sua rica produção literária. Sílvio concebia literatura como toda atividade espiritual, influência sofrida pelo germanismo de Tobias Barreto, que não reduzia aquela às belas letras. 
Para Sílvio o atraso material e cultural do país era considerado resultado de uma sociedade de caráter apático, carecendo de uma 'educação enérgica'. Consequências desse estado de coisas eram os cerca dos 16 a 18 milhões de pessoas que viviam em situação de extrema miséria devido à colonização portuguesa, colonização processada por uma raça em estado degenerativo, que não facultou um espírito de iniciativa na 'luta pela vida' como os ianques, os alemães, os franceses, os ingleses e os noruegueses. Sílvio explicava a situação de extrema pobreza e do atraso cultural do país em suas mais variadas instâncias como decorrência da colonização ibérica, apenas preocupada com a 'política alimentária', que dentre tantos malefícios trazia o mal do emprego público, etc.

Não era sem razão que sofria o Brasil desse último mal, da mania de grandeza, mostrando no exterior justamente aquilo que não éramos, pois, a raça portuguesa, há muito desligada de seu tronco, cada vez mais se degenerava, sendo responsável por uma educação apática, desinteressada pelos reais problemas políticos do país. O fator étnico era o responsável pelo quadro de miséria da maioria da população brasileira, uma vez que sua concepção de raça carregava consigo uma índole, por sua vez, portadora de características morais.

Pensador dos mais significativos do país por ter fugido a leitura romântica de irrealidade da geração dos Macedos e Alencares, Sílvio introduz um novo método de ver, estudar, pensar e projetar o Brasil, que é o método crítico. Embora seu manancial teórico fosse o de todos os homens de sua geração, Sílvio não foi um escritor preocupado em legitimar o status quo, suas ideias combatem a estrutura saquarema de espaços já reservados a pequenos grupos, a concursos públicos de reserva, ao mundo de cooptação e de dança das cadeiras, uma ordem que a geração de Sílvio lutou para que um Brasil diferente tornasse uma realidade (ALONSO, 2005)

Mesmo conhecedor das ideias de Buckle, Taine, e tantos outros autores, Silvio não simplificou suas análises da sociedade brasileira aos parâmetros raciais e mesológicos. Não é sem razão que concebia literatura em seu sentido mais amplo, no que buscou seus 'fatores condicionantes' constituídos pelo meio geográfico, pela raça, pela influência estrangeira e por todo o passado do Brasil. Tais fatores contribuíram diretamente para a explicitação da sociedade brasileira. Assim, retratou em sua vasta produção ensaística o estágio evolutivo da cultura brasileira frente os países europeus, utilizando-se do 'método comparativo' para avaliar o perfil cultural do Brasil com relação aos países europeus. Para o crítico sergipano, "a literatura brasileira não se furta às condições de toda a literatura antiga ou moderna, sendo a 
resultante de três fatores fundamentais: o meio, a raça, as correntes científicas". (ROMERO, 1960, p. 266)

Antonio Candido afirma que para Romero, "a literatura só pode ser compreendida se a estudarmos em função dos fatores condicionantes, e nunca em si mesmo" (CANDIDO, 1945, p. 156). Sílvio interpretou o Brasil de maneira rigorosamente científica, influenciado que foi pelo impacto das ciências naturais sobre a nascente sociologia, balizando suas análises a partir da lei do mais forte e dos estágios evolutivos, promovendo uma renovação literária e filosófica iniciada no Recife, da qual se considerava o introdutor no país.

No plano filosófico, combateu o espiritualismo de cunho retórico de Victor Cousin, personificado no Brasil pelo franciscano Monte Alverne, e outras figuras como Eduardo França, Gonçalves de Magalhães, Pedro Américo, Guedes Cabral e Pereira Barreto, por pensar que "o espírito crítico é uma necessidade permanente e fundamental do pensamento, é uma condição da luta pela vida na esfera das idéias”. (ROMERO, 1969, p. 60)

Sílvio inaugurou uma nova linha de interpretação no pensamento brasileiro, que tinha por base a crítica naturalista, ancorada em seus mais renomados representantes, como Taine, Scherer, Saint Beuve, etc. Para compreender a formação da história do Brasil e de seu povo, valorizou a mestiçagem e o modelo de crítica supostamente imparcial para só assim descrever o cenário do país. Sobre a crítica, afirmava que não era esta "um sistema, uma teoria, uma doutrina feita e completa, uma ciência, mas um processo, um método, um controle, que se devem aplicar às criações do espírito em todos os ramos de sua atividade" (ROMERO, 1960, p. 338)

Seria nodal para sua compreensão de Brasil a questão da mestiçagem, porque pensava que essa era a grande singularidade do país. Teoria já aludida de forma sutil por Varnhagen e de forma clara pelo alemão Martius, Romero discordou da proposta do escritor bávaro e de suas 'forças diagonais' deste porque o ganhador da monografia do IHGB apenas "aconselha aos historiadores brasileiros de contemplar os feitos das duas raças inferiores, ao lado das ações dos portugueses, e de notar as modificações nestes operadas pelo influxo dos que neles com eles coabitam". (ROMERO, 1960, p. 1531)

Concluía Sílvio que "Por isso, sua teoria é puramente descritiva" (ROMERO, 1960, p. 61) carecendo de nexo causal, porque deixa intocável a questão do mestiçamento, do meio físico, de nada adiantando aos espíritos indagadores ${ }^{2}$. A situação mestiça do país, ao contrário

\footnotetext{
${ }^{2}$ Romero dedica no primeiro volume de sua História da Literatura Brasileira um capítulo sobre as Teorias da História do Brasil e retoma de forma detida essa discussão no quinto volume desta mesma obra. Cabe apenas
} 
do pensar de ensaístas como Euclides da Cunha e Nina Rodrigues, (que começaram a escrever depois dele), ao invés de ser um mal, trazia justamente a singularidade brasileira, viabilizadora da identidade nacional, chave para a compreensão de nossa história. Mesmo se apegando ao critério racial, concebendo o homem branco como indiscutivelmente superior, Sílvio desejava em seu amplo esforço traçar o que coube a cada uma das raças na sociedade brasileira (ROMERO, 1960, 120).

Polêmico e contraditório, que uma soberba que rosnava pela inveja, com a mania de sempre querer ser o primeiro, procurou explicar o Brasil transcendendo o viés racial, o que parece ser contraditório quando admitiu que teve como mestres Lapouge e Gobineau (SCHNEIDER, 2005). Nesse sentido, via a questão da mestiçagem muito além da influência biológica: para Sílvio, a formação da sociedade brasileira jamais desprezaria a contribuição dos grupos despossuídos, residentes nos sertões ou nas vilas mais recônditas do país, nunca desconsiderando a corrupção das elites brasileiras, os jogos políticos, o fazer de conta, etc. Qualquer que fosse o problema concernente ao Brasil, lá estava Romero a discordar, apoiando-se a partir desta ou daquela ideia, querendo dar a última palavra sobre a visão que, para ele, seria a verdadeira. Tinha a mania de querer ser o primeiro, de afirmar que fora o primeiro escritor a introduzir essa ou aquela teoria no Brasil.

Foi Sílvio, como menciona Antônio Candido e Alcides Bezerra, um autor que acreditou nas Teorias e doutrinas da Ciência da época, mas seu tempo abrigava outras linhas de análise, certamente. Proclamou diversas vezes a primazia das ideias científicas sob a égide de um grupo de amigos surgido em torno da Faculdade de Direito do Recife, cuja figura mais conhecida é seu conterrâneo Tobias Barreto. Foi Sílvio um dos mais significativos interessados em apontar os problemas nacionais brasileiros, um homem polêmico que nunca aceitou retratar um Brasil que considerava irreal na compreensão da formação da sociedade do país que não cansou de escrever que tanto o amava.

\section{Uma base sociológica}

Francisco Martins de Souza designa as discussões filosóficas surgidas no grupo do Recife como Culturalismo sociológico $(2001)^{3}$ iniciado por Tobias Barreto e Sílvio Romero,

mencionar que a questão do contato das três raças já estava esboçada pelo naturalista bávaro Martius, autor premiado pelo IHGB com a dissertação Como se deve escrever a história do Brasil.

3 A primeira edição da obra se denomina O Brasil Social, publicada em 1908. Por questões didáticas, utilizaremos esta edição. Para uma abordagem cultural sobre o pensamento de Sílvio Romero, ver BEZERRA, 
continuado por Alcides Bezerra. Combatendo toda a Filosofia eclética e Metafísica, o Positivismo foi adotado por Sílvio como o elemento de síntese para a explicitação dos mais variados ramos do conhecimento. A Ciência Social de Frederic Le Play e seus discípulos, a Antroposociologia de Amom, Lapouge e Gobineau, combinadas com o Positivismo, e a Evolução foram as bases teóricas do pensamento de Sílvio Romero. Dentre a infinidade de autores das mais diversas áreas, o Evolucionismo de Spencer modelou o espírito de uma figura que buscava identificar os vícios e defeitos do país, falando de maneira extremamente objetiva. Após preterir o Positivismo de Comte, à medida que ia conhecendo as leituras de Spencer, Romero salientava a importância da escola de Le Play:

As doutrinas do Evolucionismo spenceriano tinham-me posto na pista do desdobramento natural dos vários ramos da atividade natural dos vários ramos da atividade humana. Tinham-me despertado a atenção para as formações díspares dos povos mestiçados, nomeadamente os da América do Sul, e, por esse caminho, havia sido conduzido as conclusões a que cheguei em todos os escritos acerca da minha pátria. As doutrinas da escola de Le Play, posteriormente, fizeram penetrar-me mais fundo na trama interna das formações e completar as observações exteriores do Ensino spenceriano. ${ }^{4}$ (ROMERO, 2001, p. 34)

Aderiu aos ensinamentos da Ciência Social em função do rigor da observação, priorizando a organização familiar a fim de analisar as bases da estrutura social brasileira,

A doutrina de Le Play, vigorizada por Tourville, Demolins, Rousiers, Poinsard, Pinot Descamps e toda uma plêiade de ousados investigadores, presta o inestimável serviço de ensinar e observar o povo nas diversas zonas do país na labuta especial de seu viver, de seus modos e meio de trabalho, determinar a conseqüente estrutura da família que brota naturalmente daqueles fatores primordiais e o caráter inevitável que dali advém a população.

Causa, neste, ultimo ponto, verdadeira estranheza darem alguns ignorantes, entre nós, a doutrina dessa escola social o título de reacionária, como se pudesse ter esse caráter quem ensina e proclama acima de tudo, o revigoramento do espírito de iniciativa, de autonomia pessoal, de coragem empreendedora, em suma, esse particularismo, que tem feito a fortuna dos ingleses e dos anglo-americanos (ROMERO, 2001, p. 230)

O conhecimento da Escola de Le Play ou Escola Social, composta por nomes como H. de Tourville, Ed. Demolins, P. Rousiers, A. de Preville e P. Bureau, dentre outros, divulgada pela revista La Science Sociale, influenciou Sílvio a traçar um quadro social da realidade brasileira, encontrar os males brasileiro, para só então propor seus remédios. Neste momento,

Alcides. Sílvio Romero, o pensador e o sociólogo: conferência pronunciada no dia 17 de outubro de 1929, na Sociedade Brasileira de Filosofia. Rio de Janeiro: Oficinas Gráficas do Arquivo Nacional, 1935.

${ }^{4}$ Ver ROMERO, Sílvio. A América Latina. Análise do livro de igual título do Dr. M. Bonfim. Porto: Livraria Chardron, 1906. p. 8. 
já era Sílvio adepto do Evolucionismo, que conheceu quando era aluno da Faculdade no Recife entre os anos de 1868 a 1873, fase de sua carreira intelectual de breve passagem pelo Positivismo. Os estudos de Romero Política e Estado Social são a manifestação direta da influência de Le Play em sua produção literária. Na ânsia por conhecer o Brasil e encantado pelas 'ideias novas', elaboraria Sílvio uma análise minuciosa da sociedade brasileira.

Desejava encontrar as leis que presidiam o desenvolvimento social com o objetivo de identificar a índole da nação brasileira para só assim apontar os remédios. Desse modo, realizou uma análise minuciosa da sociedade brasileira, aludindo sempre aos aspectos de formação do país. Estando o Brasil dividido em treze regiões, interessou-se em demarcar os elementos significativos da formação da sociedade brasileira. Dentro do quadro social oriundo da Escola Social, considerou a relevância das zonas sociais, o trabalho, a propriedade, os bens móveis, o salário, a economia ou poupança e o modo de família, traço mais relevante, pois de acordo com os ensinamentos de Le Play, "Esta é a base de tudo na sociedade humana: porque, além da função insubstituível e essencial de garantir a continuidade das gerações sucessivas, forma o grupo próprio para a prática do modo de existência, o núcleo legítimo da maneira normal de empregar os recursos criados pelos meios de viver" (ROMERO, 2001, p.36) Para Argeu Guimarães, filho de Artur Guimarães, conforme palavras do próprio Sílvio, dois de seus discípulos,

\begin{abstract}
ele queria ver aplicada ao Brasil idêntica pesquisa, para explicar os caracteres profundos da nossa formação. Se não desceu as minúcias de um inquérito detalhado e documentado pelo Brasil a fora, lançou, pelo menos, os lineamentos gerais desse trabalho, tomando por base o conhecimento real que possuía das populações do norte a sul, praeiros, matutos, tabaréus, caipiras, sertanejos, e a visão, a intuição sociológica de que era dotado (GUIMARAES, 1956, p. 117)
\end{abstract}

Seguidor da Escola Social de Le Play, em que funda sua visão sociológica, Sílvio almeja traçar de maneira minuciosa o quadro da sociedade brasileira em seus aspectos sociais, políticos e econômicos. Elabora um artigo $^{5}$ em que toma como parâmetro o modelo de família, descrevendo minuciosamente vinte e cinco aspectos que influenciaram a formação do caráter nacional brasileiro. Debruçando-se sobre a influência da Escola Social de Le Play, defende a Educação particularista dos países modernos, formadores de um caráter forte e de iniciativa, como os países anglo-saxões, em contraposição à Educação comunária, responsável

${ }^{5} \mathrm{O}$ artigo intitula-se Edmond Demolins transcrito de sua obra Provocações e Debates na qual iremos recorrermos inúmeras vezes. Romero levava em consideração os seguintes fatores na formação de cada tipo social: lugar, trabalho, propriedade, família, modos de existência, patronagem, comércio, culturas intelectuais, Religião, vizinhança, corporações, comuna, cidades, província, estado, expansão da raça, o estrangeiro em relação a raça, a sua História, o seu papel e posição mundial. 
pelo caráter apático ou sem iniciativa. Após sofrer influência do Espiritualismo de Jouffroy, do Positivismo de Comte, do Evolucionismo de Spencer, foi com o modelo francês de Antroposociologia que Sílvio Romero levantou o quadro de pobreza que beirava a miséria do país: “A posição do Brasil, seu verdadeiro estado social, esclarecido com o critério íntimo dos elementos primários e essenciais da vida, é que me proponho a elucidar" (ROMERO, 2001, p. 40)

Nos estudos de Política e Estado social, designação cunhada pelo próprio Sílvio quando tratou de dividir sua produção intelectual, o polígrafo analisou o quadro da sociedade brasileira composta por várias regiões. Em O Brasil Social e outros estudos sociológicos, Provocações e Debates ${ }^{6}$, O Brasil na Primeira Década do Século XX, ${ }^{7}$ Ensaios de Crítica Parlamentar $^{8}$, Introdução a Doutrina contra Doutrina ${ }^{9}$, revela os males brasileiros e busca identificar o remédio para os inúmeros problemas nacionais. Preocupado com tantos problemas, procura os remédios para um país miserável, colonizado por uma raça de índole comunária. Dessa forma, traça de maneira criteriosa, clara e contundente o quadro social, político, econômico e cultural da situação nacional, procurando falar de maneira que considerava objetiva e sem a ostensiva erudição de seus estudos de Crítica literária.

A paixão por um dia presenciar o Brasil no rol dos países modernos fez com que buscasse as últimas Teorias, adotando a que melhor se adequava para analisar o país. Dizendo-se apaixonado pelo Brasil, não tinha sentido para Sílvio o modelo de intelectual diletante, mas sim o escritor que empunha a arma à procura dos males do país. Toda uma vida dedicada a pensar o Brasil fez de Sílvio um conhecedor das diversas Teorias estrangeiras visando a entender um país que, para ele, poderia ser mostrado da maneira real e sem ilusões. Denunciou de maneira contundente as mazelas sociais do Brasil, fruto das manipulações políticas agenciadas por uma elite econômica, política e intelectual, sonhando em ver o país alcançar o status de 'moderno'. Denunciou os problemas nacionais de um Brasil miserável, arcaico, regido por verdadeiros clãs precisando urgentemente ser pensado não mais sob a exploração do homem pelo homem, mas nos quadros de um regime que pudesse prover o desenvolvimento do país. Denunciou todo um quadro social desses problemas munido com as ideias da Escola de Le Play, a fim de procurar mostrar um Brasil sem ilusões. Segundo Nelson Werneck Sodré,

\footnotetext{
${ }^{6}$ Publicado originalmente em 1909.

${ }^{7}$ Publicado originalmente em 1912.

${ }^{8}$ Publicado originalmente em 1883.

${ }^{9}$ Publicado originalmente em 1894.
} 
Sílvio Romero, interessou-se por todos os grandes problemas de seu tempo. Participou-se do debate que desencadeou em torno de cada um. Teve uma posição. Defendeu-se com a com os arremessos de seu espírito vivo e inquieto. Escrevendo uma História da Literatura Brasileira, que até hoje permanece como obra de interesse indiscutível, teve oportunidade, em suas páginas desde as primeiras, desde as de introdução, de dar a sua palavra a propósito dos assuntos que mais interessavam ao Brasil naquele momento. Por tratar de Literatura, não se viu desobrigado de apreciar os referidos assuntos, fugindo ao debate deles. Muito ao contrário, deu-lhes um lugar, chamou a atenção do público para eles, e discutiu-os conforme verificamos (SODRÉ, 1965, p. 71)

Todo o arsenal intelectual assimilado por Romero resultaria improfícuo se não aplicasse ao Brasil, com sua ambição de realizar o que a sua vista nenhum escritor havia realizado, que era a leitura do Brasil real. Problemas não faltavam para o polígrafo espreitar suas análises, com sua visão orgânico-científica balizando seu pensamento da lógica mais simples a mais composta, do menos diferenciado ao mais diferenciado. Apoiado no vasto repertório de leituras cientificas que nunca abandonou, Romero assimilou ideias somente se estas fossem viáveis para aplicar a realidade brasileira, donde a singularidade de um escritor diferente de um Machado de Assis, que veio ser um dos seus diversos desafetos. Buscou apontar e explicar os fatores constituintes do atraso brasileiro, chamando atenção para seus infinitos problemas: a corrupção política, reinante em todo o Brasil sob as mais variadas formas, corroborada pelos dirigentes da nação que desconheciam os ensinamentos da Crítica moderna como alternativa de prover o progresso do país; a condição do Ensino público; a distribuição de terras após a abolição; a questão da política econômica brasileira; a questão da imigração; a questão da mão de obra após a abolição; a questão da língua nacional como fator de integração nacional. Fazendo jus às palavras de Nelson Werneck Sodré, "Sílvio Romero, interessou-se por todos os grandes problemas de seu tempo. Participou-se do debate que se desencadeou-se em torno de cada um. Teve uma posição" (SODRÉ, 1965, p. 71)

Preocupado com os inúmeros problemas brasileiros, recorria a argumentos como os 'atavismos da raça' e os 'antecedentes históricos' que, a seu ver, justificavam a situação brasileira. O 'caráter nacional' brasileiro explicava a situação da penúria social e material do país. Responsabilizava a predominância de verdadeiros clãs políticos em todo o Brasil devido à falta de conhecimento que, por sua vez, era indissociável da raça que colonizou o Brasil já em estado de decadência.

Apesar de atinar para toda a estrutura cultural, social e econômica do país, Sílvio jamais abandonou o determinismo racial, chegando até a prever o branqueamento da sociedade brasileira. A apatia do brasileiro, a poesia lírica sem força, era resultado da 
presença do colonizador português, outra seria a situação do Brasil se o colono tivesse sido o dolicocéfalo. Como bom positivista, embora afirmasse que do Positivismo só aceitara a lei dos três estados, ardoroso evolucionista, Sílvio olhava a sociedade brasileira de forma análoga a um organismo vivo, onde cada órgão era concatenado a outro, carecendo funcionar harmonicamente. Afirma Francisco Martins de Souza que "é a esta doutrina do organicismo spenceriano que mais se atém a busca de Sílvio Romero, ligada não só ao pensamento especulativo, teórico, mas a observação dos fatos e a História do desenvolvimento humano" (SOUZA, 2001, p. 17)

O sentido teórico de suas análises e a busca irrefreada de Romero de tudo explicar pelo rigor científico descendem dos diversos autores da crítica moderna, que exaustivamente arrolava em seus trabalhos literários. Analisando a viabilidade ou não da formação de um partido operário no Brasil em Introdução a Doutrina contra Doutrina, é clara a visão de um escritor preso ao fascínio da Ciência, da sedução de toda sua geração, a Geração 1870. Sílvio Romero não separava as Ciências Morais, como a Sociologia e a História, das Ciências Naturais. Neste sentido, suas análises sociais remetem antes de tudo a leituras impregnadas dos fatores raciais e mesológicos. A raça, mais que o meio, tangencia as análises que acabam por identificar o atraso do Brasil. Cada raça é portadora de um caráter, uma Psicologia, fazendo do crítico um escritor determinista. Sua crença nas últimas ideias, geralmente oriundas da Europa, torna-o um pensador profícuo e preocupado com os problemas nacionais. Ciente das últimas Teorias europeias, buscou sempre o conhecimento que a época era considerado científico para sustentar suas análises, mostrando assim uma visão ilustrada, buscando eliminar o Brasil da situação de barbárie e pauperismo que inúmeras vezes denunciou.

Se o problema era pertinente à Educação brasileira, salientava a mania liberalizante, o excesso de realismo e acima de tudo, um Ensino que não despertava o amor à pátria. Quando tratava do Ensino brasileiro ou de alguma Teoria filosófica para analisar o Brasil, rebatia o Positivismo de Comte porque se tratava de uma corrente de ideias que impedia a formação e o desenvolvimento das Ciências, defendendo, em contrapartida, o Evolucionismo de Spencer. Pensava que a Filosofia carecia da Lógica para só assim ser possível a formação técnica responsável pela consolidação de um caráter forte em um país onde o povo era de índole apática. Em todo e qualquer debate pertinente ao estado Brasileiro, sempre se posicionara com respostas pretensamente objetivas e muitas vezes agressivas. Nessa perspectiva, faltava ao Ensino ou à Educação brasileira a disseminação dos elementos da Educação enérgica: "Se queremos continuar a ser uma gente de comunários, vivendo da política alimentaria, o ideal 
em matéria de Ensino é exatamente o que temos: se queremos, porém mudar de rumo, no sentido das grandes iniciativas, é seguir o que fazem os ingleses e aconselha Demolins " (ROMERO, 2001, p. 75)

Quando discutia a formação nacional brasileira, alegava que o país ainda não era uma nação homogênea devido à presença das três raças que inviabilizou a formação de uma identidade contempladora de um caráter nacional forte. Se a discussão era sobre a melhor forma de representação política, pensava que o caminho a seguir devia ser equivalente à índole nacional brasileira, que era incapaz de absorver as ideias parlamentaristas inglesas ou o modelo republicano americano. Afirmava que o melhor regime seria aquele que falasse a voz do povo. Ressaltava Romero que não bastava pura e simplesmente absorver ideias estrangeiras e imitá-las, a exemplo do Parlamentarismo americano e do Liberalismo sustentado por Stuart Mill.

Contrário à macaqueação ou à pura imitação com relação às ideias ou à formação de um partido operário no Brasil, discutiu a inviabilidade das propostas de Marx, Engels, Bebel e Liebknecht. Pensava Sílvio que não existia no Brasil uma sociedade dividida de maneira hierárquica indispensável à luta de classes, indispensável para a formação de um partido operário no país. Continuava fiel a um de seus mestres, no caso, Spencer, baseando-se nas leis evolucionistas, justificadora de suas ideias quando tratava de analisar a sociedade a partir dos princípios da Ciência política. Argumentava que faltavam antes de tudo estudos demográficos e estatísticos sobre o Brasil para uma discussão séria a respeito do tema.

Quando abordava a dependência econômica brasileira percebia esta como reflexo da ausência de um produto original brasileiro, uma das causas da pobreza da indústria nacional brasileira. Como bom evolucionista, posicionou-se sobre a questão da escravidão, discordando da emancipação dos escravos sem que estes se tornassem primeiramente colonos porque enfrentariam uma situação ainda mais difícil do que no regime escravista. Tomou das ideias científicas, sobretudo, o transformismo de Haeckel e o evolucionismo de Darwin para apontar um novo Brasil, combatendo a visão metafísica cristã, onde predominava a retórica propagada nas escolas e nos seminários do império brasileiro. Apesar de seu apego às teorias deterministas da ciência da época, Romero foi um homem de cultura enciclopédica de seu tempo. Devemos ressaltar que neste momento, não existia a especialização literária, predominando o modelo de escritor como Sílvio, escrevendo sobre os mais variados ramos do saber.

Sílvio tratou das inúmeras questões brasileiras, preocupado com o futuro de um país assolado por tantos problemas sociais de âmbito geral. É a partir de sua concepção 
cientificista e positivista, somada a sua visão literária que percebemos a importância e a singularidade da raça. Quando trata de investigar os autores brasileiros e a situação nacional, recorre aos elementos da Crítica moderna sempre para identificar a índole brasileira como responsável pelos inúmeros problemas para daí propor os remédios. O intuito de Romero nunca foi a análise literária que conhecemos, com áreas rigidamente formas e demarcadas, mas como bem ressalta Antonio Candido, "mas submeter a cultura do seu país a um processo integral de crítica, a fim de debastá-la das excrescências incomodas e mostrar-lhe o caminho certo - ambição que pode parecer pueril a quem não estiver familiarizado com a sua altiva confiança, e que já vem explícita nos seus primeiros livros” (CANDIDO, 1945, p. 163)

Por estar preocupado mais com a situação do 'atraso' do Brasil do que com a especificidade da gênese literária, baseia-se no evolucionismo de Spencer para analisar a situação de miséria e ignorância do povo brasileiro. Independentemente da ordem dos problemas arrolados pelo próprio Romero, podemos apreender algumas ideias centrais em seus trabalhos. O elemento racial é o principal. Sem ser o Brasil uma nação homogênea devidamente formada, em função do cadinho de raças que, segundo Sílvio, explicava o cenário de atraso do país, apostando na fusão destas levando ao branqueamento do país, alegava que era indispensável que a classe dirigente do país, formada por políticos, jornalistas e literatos, tomar conhecimento da 'real' situação do país para que só então fosse possível transformá-lo em uma nação moderna.

Faltava ao Brasil, na visão de Romero, um sentimento nacional forte, que tinha suas raízes no meio, na raça, e nos antecedentes históricos. Somente conhecendo o 'caráter nacional' brasileiro seria possível identificar os reais problemas do país, principal viabilizador de uma mudança de ordem estrutural. Pensar o Brasil como nação era, antes de tudo, identificar as raças formadoras da sociedade brasileira para, só assim, buscar a identidade de um povo mestiço! Romero acreditava na evolução transformista e na lei do mais forte. Desse modo, a origem dos males brasileiros e o motivo principal do país não ter-se constituído ainda como nação tinha ligação direta com a 'formação comunária', responsável pelas mazelas sociais e políticas do país, justificava a pobreza “dos doze milhões de brasileiros residentes nas matas, sertões, campos gerais, chapadas, chapadões, planaltos, fora das restritas gentes das grandes vilas e cidades, da costa ou mesmo do centro" (ROMERO, 2001, p. 88).

Do cruzamento das raças, afirmava que resultava o caráter deliquescente do brasileiro, levando-o a investigar as inúmeras áreas do país, influenciado pela Escola de Ciência Social, buscando as 'raízes do mal', embora afirmasse que alguns problemas eram insolúveis. Aqui, reside uma dura crítica oriunda da historiografia tradicional, como também atual: perceber 
Silvio Romero como um adepto das teorias estrangeiras de maneira acrítica, construindo a idéia de um escritor que desconhecia seu próprio país, o que tanto combateu alegando a macaqueação ou imitação das idéias estrangeiras porque discordava da imagem do Brasil divulgada pela elite dirigente, corroborada por jornalistas e escritores. Dizia Romero que o Brasil não estava preparado para receber as últimas ideias da Crítica moderna, nem era o Brasil aquilo que nossos dirigentes defendiam, resultado de uma certa 'embriaguez dionisíaca'. As raízes dos males brasileiros eram o desconhecimento do próprio país, como lembrava o polígrafo, "a mania de passar pelo que não somos" (ROMERO, 1910). Como um profundo conhecedor da realidade nacional, o crítico literário apontava o estado de ignorância, pauperismo, miséria e opressão do povo brasileiro: "Nosso maior mal, disse, é não termos a consciência positiva do que realmente somos e, muito ao invés disso, darmo-nos a nossos próprios olhos uma superioridade, uma grandeza, um poderio, um progresso, uma cultura, um adiantamento, uns predicados quase sem par por aí além entre as demais nações” (ROMERO, 1910, p. 105)

A imitação, para Romero era consequência de uma elite que pensava, representava e divulgava no exterior aquilo que o Brasil não era, era a mania de passar por aquilo que não somos, mascarando os reais problemas do país. Somava-se a isto o desconhecimento dos preceitos da Crítica moderna, o que só reforçava esse quadro de atraso. O ilusionismo, sentido das duras investidas de Romero, na ânsia de retratar um Brasil sem ilusões, foi motivo de seus estudos as diversas zonas sociais brasileiras, influenciado pela Escola Social, acreditando, assim, encontrar as raízes do mal, para prover o progresso do país. Em sua análise sociológica, concluía que:

O maior mal do Brasil, e não é coisa que lhe seja exclusivamente peculiar, porque muitos outros povos participam do mesmo achaque: é pretendermos ser, como nação, como todo político-social, o que não somos realmente.

É um estudo de Psicologia popular, de anthroposociologia nacional que não tem sido feito e do qual darei apenas algumas linhas gerais (ROMERO, 1908, p. 102)

Sílvio se prendia ao caráter racial, esteio maior de sua incessante busca do Brasil e do brasileiro. O elemento racial, que para o escritor sacramentava a psicologia nacional aparecia como preponderante, norteando as análises acerca de toda a estrutura social brasileira. Uma série de problemas estavam ligadas à raça, compor exemplo, a imitação

É que quando discursamos de ideias e doutrinas, somos repetidores das teorias que julgamos mais avançadas, nesse prurido infantil, muito nosso, de nos mostrarmos muito inteligentes e sabedores; e, quando aplicamos, quando descemos à prática daquelas mesmas instituições que copiamos dos outros, 
revelamo-nos tais quais somos: os atavismos acumulados no povo pela_raça e pela História surgem em cada um de nós; o tipo meio selvagem aparece.

É regra que não falha, nem pode falhar.

Destarte, todos os nossos pretendidos chefes e guias políticos são-no de fato, não, como ingenuamente todos supõem, pelas ideias que pregam, ideias de que são autores, mas sim pelo modo como as realizam, pela feição pessoal que lhes dão, quando as desvirtuam na prática (ROMERO, 2001, p. 185)

Em que pesem seus antagonismos e contradições somados ao lado pragmático de suas ideias, cabe-nos apenas perceber Silvio Romero, como nos lembra Antonio Candido e Alcides Bezerra, como um exemplo dos jovens bacharéis saídos recentemente das academias, empolgados e acreditando de maneira desmesurada na verdade científica. A visão de Sílvio Romero é de totalidade orgânica, de uma sociedade vista a imagem e semelhança de um organismo com seus órgãos, regida por movimentos que jamais podem estrangular a harmonia funcionalista. Suas ideias só possuem sentido quando imersas nesse projeto ilustrado que uma pequena elite intelectual possuía, que tinha por base os mesmos rigores das leis científicas. Somente identificando as causas ou os elementos formadores do atraso brasileiro é que se torna compreensível a visão de Romero.

Trabalhava o ensaísta sergipano a partir da terminologia em voga no momento, sob a perspectiva de caráter nacional. Caráter este que foi a grande ideologia presenciada no momento de formação das Ciências Sociais no Brasil, quando, por meio dos ditames científicos, se buscou simultaneamente identificar a situação do país e forjar os elementos de brasilidade (CANDIDO, 1959)

Nessa perspectiva, somente com amor à pátria seria possível transformar a realidade miserável ou pobre da população brasileira, algo que os dirigentes da nação não possuíam, como o clã dos Lucenas, os Pinheiros ou os Borges de Medeiros. Como se não bastasse o quadro de atraso do país, somado ao nacionalismo de Sílvio, alegava como já mencionado que a raça brasileira era apática devido sua herança ibero latina, que colonizou o Brasil já distante de seu tronco, se encontrando assim em estado degenerado. De sua pena e de sua paixão pelo Brasil, temperadas pela presença num cenário de forte disputa entre intelectuais, surgem às duras críticas que moveu a diversos escritores, como por exemplo, Euclides da Cunha, José Veríssimo, Manoel Bomfim, dizendo falar somente a verdade, pouco se preocupando com a maneira de dirigir suas argumentações (COSTA FILHO, 2018).

Figura polêmica, homem que dava a mão à palmatória, Romero inúmeras vezes disse ser vítima de perseguição e de calúnia. Talvez seja essa a razão para seus ataques a seus 
adversários. Sempre apelava para o conhecimento real dos fatos como se este fosse um grande laboratório, como se fosse possível comprovar os antecedentes históricos do país. Ressaltava a cadeia dos fatos históricos brasileiros como resultado das leis sociológicas resguardadas sob o evolucionismo de Spencer, almejando um dia ver contada a História do Brasil, sonhando com a formação da nação brasileira. Evolucionista convicto, falava Romero o que pregavam as leis evolutivas: argumentava que só falava a partir dos fatos, daquilo que aconteceu, dispensando discussões de cunho estético que não apontassem os caminhos para as mudanças que tanto arrolou em seus livros, lutando durante toda a sua vida. Exímio conhecedor da Literatura e da História universal, falava apontando fatos, ponto de partida para toda e qualquer discussão, porque acreditava na autoridade da ciência. Diante dos inúmeros problemas que constituíam o atraso brasileiro, falava a partir da alma nacional, do gênio da História, da Psicologia dos povos, uma vez que sua concepção de escritor era a do intelectual que deveria falar a verdade, o homem que forma opinião, que cabe a denúncia dos problemas de seu país. Acreditava tenazmente na alma brasileira, índole ou psicologia nacional, razão de sua incessante busca pelos inúmeros problemas do país enquanto sociedade analfabeta e miserável dirigida de norte a sul pelas vinte e três oligarquias dominantes. Somente alterando o caráter nacional brasileiro de índole apática por meio de uma educação particularista, seria possível mudar o quadro de miséria mental, social, política e cultural de nossa sociedade.

Investiu contra o Ensino retórico de cunho espiritualista personificado em Cousin, aderindo primeiramente ao Positivismo, mas sempre insistindo no conhecimento da Escola Social, no conhecimento de Le Play e na Antroposociologia, alternativa que mudaria o caráter ou a índole apática do brasileiro. Tendo por base a preocupação com o caráter nacional brasileiro, acreditando nele sem questionamento, traçaria suas análises e a categoria racial entrava aqui de forma determinista. Criticava os dirigentes da nação (escritores e jornalistas), por não conhecerem nem a realidade do próprio país nem o caráter do povo ou a psicologia nacional. Adotando o método de observação direta proposta pela escola de Le Play e tomando conhecimento dos trabalhos de teóricos que tinham como objeto o campo conceitual de psicologia dos povos, como Fouillé, Greard, Lavisse, Liar, Guyau, perguntava Romero se o ensino brasileiro facultaria o amor à pátria,

Temos nós, brasileiros, de longe ou de perto, trabalhado em igual sentido? Ai de nós!-que somos forçados a confessar o nosso criminoso descuido neste ponto vital. Povo semi-barbaro, tomado em seu conjunto, povo de analfabetos em sua quase totalidade, nós brasileiros, sofremos da pior das moléstias: a mania liberalizante.

Esta fatal moléstia, denunciadora da leviandade do caráter nacional, que não tem fixidez, firmeza, segurança; que não assenta na rocha indestrutível de 
um complexo de tradições que sejam o sangue de nosso sangue, a base adamantina de nossa alma; esta fatal moléstia já nos tem feito amargar e há de ser-nos fatalissima nos tempos por vir (ROMERO, 1900, p. 169).

Nessa perspectiva, a apatia do brasileiro era oriunda da nossa formação étnica, responsável pelo atraso social, político e cultural. A mania liberalizante, resultado da falta de conhecimento do verdadeiro Brasil, explicava para Romero o motivo de tanta macaqueação, sobretudo, da imitação francesa, uma vez que não possuía o brasileiro uma índole ou psicologia preparada para lidar com as instituições vigentes nas nações modernas. Faltava ao Brasil um ensino que despertasse o sentimento nacional: "Falta-nos a emulação, a consciência de estarmos a colaborar numa grande obra nacional ou humana, o entusiasmo do sacrifício as nobres causas" (ROMERO, 2001, p. 144)

Dizendo-se farto de tantos discursos políticos e literários, discordava de Euclides da Cunha, que "reclamava que a Evolução biológica reclama a garantia da Evolução social" (ROMERO, 2001, p. 86). Em sua análise, o autor de Os Sertões pensava que as populações sertanejas iriam desaparecer devido à inferioridade biológica com a vinda de imigrantes. Romero reconhecia a existência de dois Brasis, mas não pensava na futura extinção das populações sertanejas como nos moldes de Euclides, que via a mestiçagem como um fator de degeneração. Reconhecendo as inúmeras zonas sociais do país, seria necessário falar dos caipiras, tabaréus, caiçaras, matutos, povo que, para Euclides da Cunha iria desaparecer. O conhecimento de temas, autores e visões científicas oferecidas pela Crítica moderna facultaria o conhecimento real do país frente a uma estrutura social miserável, responsável por ambiguidades no Brasil, como ter poucos intelectuais vivendo em uma nação composta por milhões de miseráveis e analfabetos, assegurava Romero. Sendo o ensino brasileiro produto da decadente herança portuguesa, baseava-se nos exemplos de França, Itália, Inglaterra, Alemanha, uma vez que nesses países os escritores contribuíram para o despertar de uma educação patriótica e uma índole de iniciativa. Em O problema brasileiro em 1891, analisava a situação nacional chamando atenção para a volta do sebastianismo deixando claro que o país em nada mudou: "Na política, na vida social, nas Letras, nas Artes, na Ciência, no jornalismo, por todos os lados e por todas as formas por que se costuma revelar a alma de um povo, a voz brasileira tem ainda o mesmo som, o mesmo gaguejar de quem não tem consciência e nem sabe o que quer" (ROMERO, 2002, p. 359). Alertava para a volta da monarquia e descrevia a corrupção do governo provisório, herdada do lucenismo, “As mesmas questiúnculas, os mesmos vícios, os mesmos pequenos interesses pessoais, as mesmas chicanas, as mesmas 
pepineiras, e, para tudo dizer numa só palavra, a mesma desengraçada comedia representada quase pelos mesmos atores" (ROMERO, 2002, p. 359)

Fervoroso nacionalista, Romero afirmava que o Brasil precisava ser dirigido por homens de um caráter severo, pois sequer o povo brasileiro conhecia a História de seu próprio país. Ressaltava que faltavam documentos para narrar à História literária do Brasil respaldando-se na tônica positivista de que 'sem documentos não há história'. Definidor de rumos políticos do país, perguntava pela melhor forma de representação política a seguir. Segundo suas análises, o caráter nacional não estava em condições de acolher o sistema representativo, o regime parlamentarista, como nos moldes do federalismo inglês e americano, encontrava-se acima da índole brasileira,

\begin{abstract}
Assim como o instinto de conservação da raça sugere o tuana, o oligarca, o caudilho, o clã dirigente e compressor, em oposição ao tribuno, o retórico, o fantasista liberalizante, pela mesma forma ele mostra bem claro, nessas ásperas provanças que nos inflige, que o federalismo democrático e livre está muito acima de nosso estado social, o qual não deve ser aferido pelos literatos da Academia, os eruditos do Instituto Histórico, os cientistas da Politécnica ou das Faculdades de Medicina e Direito (ROMERO, 2002, p. 189)
\end{abstract}

Sempre que analisava o Brasil, partia do método da Ciência Social para atingir a índole da nação e então identificar os elementos do atraso e propor suas soluções,

\begin{abstract}
Basta-me consignar que o nosso estremecido povo brasileiro apresenta a sintomatologia geral das noções a cujo grupo pertence esse grande número de povos de índole e formação comunária, especialmente os latinos americanos, que tem de suportar a nova concorrência das nações de formação particularista, colocadas atualmente a frente da civilização industrial do nosso tempo: ingleses, alemães, americanos, canadenses, australianos, flamengos, holandeses, franceses do norte, povos que retêm em suas mãos os capitais movimentadores do mundo moderno (ROMERO, 2001, p. 87)
\end{abstract}

Algumas vezes contraditório, quanto a melhor forma de governo, Romero posicionava-se a favor de um federalismo onde o poder autoritário dos Pedros fosse extinto, dando maior liberdade às províncias, mas foi justamente essa liberdade a razão para atuação e formação das oligarquias estaduais, com o advento da ordem republicana. Nesse sentido, o Brasil republicano só confirmou os inúmeros problemas nacionais ligados à 'formação comunária'.

A falta de seriedade ou comprometimento por parte dos dirigentes da nação, segundo Romero, era resultado desta formação comunária em que a população pobre e analfabeta dependia do proprietário de terra para sobreviver. Aqueles que deveriam se contrapor a toda 
sorte de desmandos políticos eram justamente os próprios políticos, jornalistas e escritores, tornando-se a classe mais perseguida por Romero.

O estado de pobreza da maior parte do povo brasileiro devia-se a essa formação incapaz do espírito de iniciativa, que somente a Nova Educação seria capaz de reparar. Somavam-se a esses fatores o caráter étnico e histórico de nossa população, causas de toda a sorte dos problemas nacionais. Toda a 'raiz do mal' brasileiro devia-se à raça colonizadora, que em seu país, dedicava-se ao comércio em uma determinada região, ao pastoreio noutras e no resto do território nacional vivia da 'cultura doce' que é uma quase jardinagem (ROMERO, 2001, p. 88)

No Brasil, a raça colonizadora recorreu ao índio, ao negro e aos mestiços que, para Sílvio, eram raças alheias ao trabalho agrícola, "mas todo o mundo não podia ser no campo senhor de engenho, fazendeiro de gado ou de café” (ROMERO, 2001, p. 88). Daí a razão da pobreza das populações campestres, que viviam sob o peso do chefe de terra ou do coronel, responsáveis pelas práticas mais absurdas de corrupção e mandonismo. Sem ser o brasileiro uma raça já formada, de índole passiva, várias características emergiam daí, sendo a principal destas a cegueira ou o desinteresse pelas verdadeiras questões políticas, alegava Romero. Com uma população analfabeta, na qual as pessoas nada levavam a sério os problemas políticos brasileiros, política no Brasil nada mais era que politiquice.

Citando vários oligarcas em seus respectivos clãs estaduais, apontava Romero à falta de seriedade por parte dos dirigentes da nação brasileira, uma vez que política para os políticos brasileiros "continua a ser a Arte de mentir habilmente" (ROMERO, 2001, p. 88). A psicologia do brasileiro necessitava de mudanças para que estivesse em condições sociais e culturais de lidar com a ordem republicana, regime defendido não apenas por Romero, mas por grande parte dos escritores de sua geração, pois alegavam que com o advento da ordem republicana surgiriam mais oportunidades políticas, diferente do mundo fechado e de prebendas dominado pela política saquarema.

\section{E o mestiço no Brasil?}

Se por um lado Sílvio Romero é considerado um escritor determinista porque atribui o atraso do país ao caráter racial, num Brasil composto por mestiços, afirma que é justamente este a singularidade que pode levar o Brasil ao progresso. Os ensinamentos da Escola Social podem reparar o caráter apático do brasileiro, que explica a preocupação do brasileiro em comer. Outro desdobramento de nosso caráter era a presença das oligarquias na cena política 
do país, em que milhares de brasileiros eram totalmente despossuídos e desassistidos, ficando a mercê dos chefes locais. Outro problema era uma pequena elite de intelectuais iludindo-se pela mania de grandeza, pensando um Brasil de Haia, com seus finos discursos políticos e literários, mais preocupada com a abertura de ruas e avenidas do que com a realidade de pobreza da população.

Os problemas brasileiros que Sílvio datava em 1891 já de desenrolavam há muito tempo na história nacional,

Um falso pudor vela-nos a grosseria dos fatos; a tendência da raça para a facilidade atraente das ideias geradas e simplistas põe-se em ação; o orgulho latente em todas as almas, sem sermos já tão bons como os melhores, levanos não só a copiar as instituições dos mais aptos, como até a lançar-lhes em muitos casos a barra adiante. Daí essas constituições e leis que muitas vezes são verdadeiras obras de Teoria, sem aplicabilidade prática (ROMERO, 2001, p. 184)

Sílvio salientava a ausência de seriedade dos políticos, que não tinham a menor paixão pelas coisas nacionais, decorrente de suas falácias, da verborragia de literatos e jornalistas, "as três classes que têm mais de perto dirigido a vida mental e pública do povo brasileiro" (ROMERO, 2001, p. 184).

Defendendo a formação particularista responsável pelo crescimento das grandes nações devido seu espírito de iniciativa, salientava Romero ser a ausência desse fator a causa principal do atraso brasileiro nos mais diversos aspectos. Como consequência dessa formação existia no Brasil toda uma massa despossuída e miserável, sustentando políticos, formadores de verdadeiros clãs. Os políticos brasileiros buscavam a política como meio de prevaricação, realizando as mais diversas formas de corrupção, ao passo que 9/10 da população buscava apenas sobreviver, almejando pequenos cargos públicos. A maioria da população miserável das vilas e cidades dependia exclusivamente dos chefes de partido, fazendeiros, vigários das vilas, juízes de Direito, advogados, médicos.

Nesse sentido, o que cabia ao Estado era somente alimentar grande parte da população em função dos poucos que trabalhavam, visto ser o funcionalismo público a única forma de sobrevivência. Somente La Nouvelle Éducation possibilitaria alterar a índole do brasileiro, espalhando-a nas diversas zonas sociais do país. Analisava o pensamento e a importância de Demolins, mal lido e por isso mesmo desconhecido no Brasil pelos "crichanás da Crítica brasileira”, (ROMERO, 2001, p. 72) referindo-se a José Veríssimo e Euclides da Cunha, no que resultava a visão ilusionista do país dirigido por políticos corruptos como o oligarca Pinheiro Machado, do Rio Grande do Sul, e outros do Brasil. 
A adesão de Sílvio Romero ao pensamento da Ciência Social se dá por uma questão muito óbvia: "Como quer que seja, os méritos da escola, a despeito desta e doutras divergências, se me antolham preciosíssimos para quem quer conhecer a fundo um país qualquer e a gente que o habita" (ROMERO, 1960, p. 190). Sílvio abordava a questão da Nova Educação aplicada em algumas escolas inglesas estabelecidas no campo, responsáveis pela formação do caráter de iniciativa, em contraposição às sociedades de formação comunária, responsável pelo caráter apático. Lembrava, em História da Literatura Brasileira, depois de ultrapassar as teias do Positivismo em seu 'círculo de ferro', que "Os processos da escola de Le Play fizeram-me penetrar mais fundo na trama interna das formações sociais e completar as observações exteriores de Ensino spcenceriano. É uma confirmação, em última instância, de conclusões obtidas por outros meios e estradas" (ROMERO, 1960, p. 189)

Toda a adesão de Sílvio Romero à Escola de Le Play era uma forma de ver o Brasil e discutir com a geração de sua época (COSTA FILHO, 2016), influenciando escritores futuros como Oliveira Viana, Monteiro Lobato, Cassiano Ricardo, Paulo Prado, Gilberto Freire, Gustavo Barroso, etc, por sua convicção na potencialidade do homem branco, a voz do colonizador, o homem superior, que sem ele a nação brasileira não se formaria (COSTA FILHO, 2017).

\section{Considerações finais}

Pensador dos mais significativos do país por ter alongado as influências européias aos inúmeros problemas nacionais, Sílvio é uma figura proeminente da geração científica de sua época por ter inovado a maneira de interpretar o Brasil, após as análises românticas legitimadoras de uma sociedade hierárquica em razão da economia escrava. Embora seu manancial teórico fosse o de todos os homens de sua geração, Sílvio não foi um escritor preocupado em legitimar o status quo, escrevendo da maneira mais simples para que a elite brasileira soubesse aquilo que Romero considerava serem as verdadeiras raízes dos males do país.

Por mais que se baseie nos preceitos do Determinismo e do Evolucionismo, Sílvio vai além da mera análise determinista, seja da raça ou do meio climático. Mesmo reconhecendo a contribuição dos portugueses, busca encontrar a singularidade brasileira. Seus estudos folclóricos deixam clara a importância que atribuía aos grupos mais simples dos sertões e vilas brasileiras, como pescadores e vaqueiros. Sílvio moveu severas críticas à elite do país, 
ao ensino de cunho retórico, à presença das oligarquias presente em todo o país, à dependência da economia brasileira, etc.

Personagem polêmico e nacionalista, falava que não escrevia para agradar, lembrando Villemain. Justificava-se que em nenhum momento escrevia em benefício próprio, já prevendo futuras e possíveis reprovações como de fato aconteceria. Afirmava sempre falar em nome da verdade, como um justiceiro julgando tudo e todos. Chamou atenção diversas vezes contra o mal da cópia e de uma história brasileira fantasiosa, como a criada e interpretada pela geração do romantismo, que traçou um quadro nacional que ele considerava mentiroso, irreal, omitindo a participação do negro na história. Como outros integrantes de sua geração, sustentou que para o Brasil alcançar o estágio 'moderno' ou 'civilizado', à imagem e semelhança dos países europeus, seria necessário antes de tudo descortinar e denunciar os verdadeiros problemas brasileiros para só então assimilar ideias ou instituições condizentes com o estágio da raça (índole) do brasileiro.

A ânsia por ver seu país como uma nação moderna foi a razão para tanta confusão de ideias por parte de um escritor que era um revoltado contra o sistema, como chegou a afirmar, denunciando a camaradagem literária da Corte, onde somente com a ajuda dos medalhões era possível adentrar as rodas literárias, o jornalismo literário e alcançar cargos públicos. O momento histórico experimentado por Romero fez dele um homem político na medida em que processava uma ruptura na forma de conceber o intelectual frente a sua nação.

Essa nova maneira de ver a sociedade brasileira tinha estreita implicação com o conjunto de transformações econômicas ocorridas na Europa, abrangendo a maioria dos países dependentes do mercado europeu. Sílvio Romero, assim como tantos polígrafos de seu tempo, insere-se nessa conjuntura de pensar um Brasil sem escravidão, projetando a formação de uma nação, preocupando-se, portanto com a infinidade de problemas nacionais, que segundo ele, explicavam o atraso do país.

\section{Fontes}

ROMERO, Silvio. Estudos de Literatura Contemporânea. (Edição comemorativa). Rio de Janeiro: Imago Editora; Aracaju; Sergipe: Universidade Federal de Sergipe, 2002. (1 ${ }^{\text {a }}$ Ed. 1884)

Doutrina contra doutrina. Companhia das Letras, 2001. (1 ${ }^{\mathrm{a}}$. Ed.1894)

História da Literatura Brasileira. I, II, III. Rio de Janeiro: José Olímpio, 1960. (1ª

Ed. 1888)

Ed. 1908)

O Brasil social e outros estudos sociológicos. Brasília: Senado Federal, 2001. (1 
Obra Filosófica. Rio de Janeiro: José Olímpio, 1969.

- Provocações e debates. Contribuições para o estudo do Brasil Social. Porto:

Imprensa Moderna, 1908.

\section{Referências bibliográficas}

ALONSO, Ângela. Ideias em movimento: a geração 1870 na crise do Brasil - Império. São Paulo: Paz e Terra, 2002.

BEZERRA, Alcides. Sílvio Romero, o pensador e o sociólogo: conferência pronunciada no dia 17 de outubro de 1929, na Sociedade Brasileira de Filosofia. Rio de Janeiro: Oficinas Gráficas do Arquivo Nacional, 1935.

CANDIDO, Antonio. A Sociologia no Brasil. Tempo Social, 271/301, V.18, nª 1, 1959. . Introdução ao método crítico de Silvio Romero. São Paulo: Tese/FFLCH, 1945.

COSTA FILHO, Cícero João da. Raça e evolucionismo, as Ciências Sociais no Brasil: querela entre Sílvio Romero e Manoel Bonfim em torno da herança portuguesa na formação brasileira. Intelligere, n. 6, p. 26, 31 dez. 2018.

2016.

.Sílvio Romero: literatura, raça e política (1851-1914). São Paulo: Porto de Ideias,

- 'Raízes raciais' do Projeto integralista (nacional) de Gustavo Barroso: o preconceito, a intolerância e o racismo para com a figura do judeu no Brasil da década 1930. Revista Caminhos de História, v.22, n², jul/dez, 2017, PPGH, Unimontes.

GUIMARÃES, Argeu. Presença de Silvio Romero. Rio de Janeiro: Organização Simões, 1955.

SCHNEIDER, Alberto Luiz. Sílvio Romero, hermeneuta do Brasil. São Paulo: Annablume, 2005.

SODRÉ, Nelson Werneck. A ideologia do colonialismo: seus reflexos no pensamento brasileiro. $2^{\text {a }}$ Ed. Rio de Janeiro: Civilização Brasileira, 1965.

SOUZA, Francisco Martins de. A questão teórica da cultura na Escola do Recife. Prefácio. In: O Brasil Social. Brasília: Senado Federal, 2001. (1 ${ }^{\text {a }}$ Ed. 1908). 